\title{
NANOTECNOLOGIA: ASPECTOS GERAIS E POTENCIAL DE APLICAÇÃO EM CATÁLISE
}

\author{
Hadma Sousa Ferreira e Maria do Carmo Rangel* \\ Instituto de Química, Universidade Federal da Bahia, Campus Universitário de Ondina, 40170-280 Salvador - BA, Brasil
}

Recebido em 14/4/08; aceito em 18/2/09; publicado na web em 4/8/09

\begin{abstract}
NANOTECHNOLOGY: GENERAL ASPECTS AND POTENTIAL APPLICATIONS IN CATALYSIS. In recent years nanomaterials, such as metallic nanoparticles, nanowires, nanotapes, nanotubes and nanocomposites, have attracted increasing interest for several technological applications. In catalysis, the great potential of nanomaterials is related to the high catalytic activity exhibited by these materials as a function of the high surface/volume ratio when the particles acquire diameter below $5 \mathrm{~nm}$. In this work, a review about concepts and background of nanoscience and nanotechnology is presented with emphasis in catalysis. Special attention is given to gold nanoparticles and carbon nanotubes, focusing the properties and characteristics of these materials in several catalytic reactions.
\end{abstract}

Keywords: nanocatalysts; gold nanoparticles; carbon nanotubes.

\section{INTRODUÇÃO}

A ciência e tecnologia em nanoescala têm atraído considerável atenção nos últimos anos, pela expectativa do impacto que os materiais nanoestruturados podem causar na melhoria da qualidade de vida e na preservação do meio ambiente. Espera-se que o avanço da nanociência e da nanotecnologia estimule não apenas a exploração de novos fenômenos e novas teorias, mas também conduza a uma revolução industrial, se tornando a nova força motora do crescimento econômico neste século. ${ }^{1}$

A pesquisa e o desenvolvimento, em nanotecnologia, visam a manipular estruturas em nanoescala e integrá-las para formar componentes e sistemas maiores. As possibilidades são quase infinitas e se prevê que a nanotecnologia exerça um efeito mais profundo, na sociedade do futuro, que o impacto causado pelos automóveis, aviões, televisões e computadores no século XX. Espera-se que muitos dos importantes impactos devam vir do aumento das velocidades das reações, através do uso de nanocatalisadores e da integração da eletrônica molecular com a tecnologia avançada do silício. ${ }^{2}$

Os investimentos em nanociência e nanotecnologia marcam presença em todas as áreas do conhecimento e representam um investimento da ordem de bilhões de dólares, por parte dos órgãos e agências de fomento em pesquisa e desenvolvimento em todo o mundo. $\mathrm{O}$ desenvolvimento de nanopartículas movimenta recursos da ordem de US\$ 40 bilhões anuais. Os Estados Unidos da América, o Japão, a China e a Coréia do Sul são os países que mais investem em programas e patentes em nanotecnologia. ${ }^{3}$ No Brasil, o Programa Nacional de Desenvolvimento em Nanociência e Nanotecnologia investiu U\$ 30 milhões, no período de 2005 a 2006. Com relação à produção científica mundial, estudos preliminares indicaram um crescimento com cerca de 130 mil artigos publicados, a partir de 1994, relacionados a eixos temáticos em nanociência e nanotecnologia. ${ }^{4}$

Em 2008, apenas no mês de fevereiro, o termo nanotecnologia apareceu na Web of Science e no Science Direct com 14.951 e 1.730 artigos científicos, respectivamente; por sua vez, o termo nanomaterial foi citado em 615 e 255 artigos, respectivamente. Isto significa que está ocorrendo uma extraordinária divulgação de conhecimento científico, importante para o desenvolvimento da sociedade. Entretanto, alguns desafios em nanociência e nanotecnologia ainda devem ser superados através de parcerias e estratégias, por parte dos setores acadêmico e

*e-mail: mcarmov@ufba.br industrial, de forma que a nanotecnologia possa realmente cumprir seu papel no contexto sócio-econômico e tecnológico mundial. ${ }^{4}$

Espera-se que a nanotecnologia possa proporcionar a geração de novos produtos e novas oportunidades de mercado, através da integração da ciência e tecnologia. A maioria das indústrias atuais irá se beneficiar com as inovações da nanotecnologia. As colaborações e interações entre indústria, academia e instituições governamentais, em escala mundial, irão acelerar o desenvolvimento de novos produtos. O tradicional modelo de negócio de larga escala deverá ser revisto de modo a considerar o elevado valor agregado dos nanomateriais e o valor social deverá incluir um menor impacto ambiental na manufatura dos produtos. ${ }^{5}$ Os processos deverão ser mais limpos e com maior eficiência no uso da energia e, possivelmente, de novas fontes renováveis. O consumidor irá se beneficiar pela diversidade de produtos baseados na nanotecnologia, que irão melhorar a qualidade de vida das pessoas em todo o mundo.

Alguns produtos em nanoescala já estão sendo comercializados, tais como dióxido de titânio, ouro, prata e cobre que, adicionados aos plásticos, tintas e outros materiais, melhoraram o seu desempenho. Outros produtos estão próximos da comercialização, como veículos de transportes de drogas no corpo humano e nanotubos de carbono. ${ }^{6}$ Para permitir a ampla comercialização dos produtos baseados na nanotecnologia, deve-se procurar atender às seguintes demandas: nanossíntese: construção de blocos em nanoescala incluindo nanopartículas, nanotubos e materiais nanoestruturados; nanofabricação e nanoprocessamento: manipulação e processamento em nanoescala dos blocos construídos para uma dada finalidade; nanoincorporação: incorporação em nanoescala dos blocos até obter a forma do produto final, incluindo compósitos, materiais eletrônicos e dispositivos biomédicos e nanocaracterização - medida e caracterização das propriedades básicas dos blocos em nanoescala ou das formas dos produtos finais, assim como de processos de manufatura. ${ }^{5,7,8}$

\section{ASPECTOS GERAIS DA NANOCIÊNCIA E NANOTECNOLOGIA}

O termo nanotecnologia foi introduzido pelo engenheiro japonês Norio Taniguchi, para designar uma nova tecnologia que ia além do controle de materiais e da engenharia em microescala. Entretanto, o significado do termo atualmente se aproxima mais da formulação de Eric Drexler, que corresponde à metodologia de processamento envolvendo a manipulação átomo a átomo. Por outro lado, a na- 
nociência se refere ao estudo do fenômeno e da manipulação de sistemas físicos que produzam informações significativas (isto é, diferenças perceptíveis), em uma escala conhecida como nano $\left(10^{-9}\right.$ $\mathrm{m}=1 \mathrm{~nm}$ ) com comprimentos típicos que não excedam $100 \mathrm{~nm}$ em comprimento em pelo menos uma direção. Portanto, a nanotecnologia foca o projeto, caracterização, produção e aplicação de sistemas e componentes em nanoescala. ${ }^{9}$

Considerando-se os processos químicos, físicos e biológicos que ocorrem na natureza, é possível identificar a presença da nanotecnologia em períodos remotos da história da humanidade. Há aproximadamente 4000 anos A.C., os alquimistas egípcios utilizavam o "elixir de ouro" para estimular a mente e restaurar a juventude. O famoso "elixir da longa vida", era constituído na realidade por partículas de ouro em suspensão com tamanho da ordem de 1-100 nm. ${ }^{10}$

Os chineses, embora sem ter consciência disso, já aplicavam a nanotecnologia, ao empregarem nanopartículas de carvão em solução aquosa para produzir a tinta nanquim. Na Europa, o colorido dos vitrais das igrejas medievais, tão ricamente trabalhados pelos artesões, era o resultado da formulação do vidro com nanopartículas de ouro. A famosa Taça de Licurgus, do século IV d.C, que exibe uma cor verde quando a luz é refletida, mas é vermelha sob luz transmitida, é na realidade constituída por nanopartículas de ouro e prata. ${ }^{10}$ No século XIX, Michael Faraday mostrou a relação entre as propriedades e o tamanho de partículas de ouro, observando que esse tamanho influenciava na absorção de luz. ${ }^{11}$ Dessa forma, é possível obter materiais baseados em ouro em diferentes cores, dependendo do tamanho das partículas. Em sua forma natural, o ouro exibe uma coloração amarela porém, dependendo do tamanho das partículas, ele pode se mostrar negro, rubi ou arroxeado. ${ }^{12}$

Apesar da nanotecnologia estar presente na natureza há milhares de anos, foi na década de 50 que o físico americano Richard Feynman, em conferência na Reunião da Sociedade Americana de Física, sugeriu a construção e a manipulação, átomo a átomo, de objetos em escala nanométrica. Intitulada "Há mais espaços lá embaixo", a conferência de Feynman representou uma nova concepção em nanociência e nanotecnologia. Somente mais tarde, na década de 80, com a descoberta dos fulerenos, por Krotoe, posteriormente, a síntese dos nanotubos de carbono por Iijima, os temas em nanociência e nanotecnologia, antes vistos como ficção, passaram a ser tratados com maior seriedade..$^{13,14}$

Por definição, os materiais nanoestruturados apresentam, pelo menos, uma de suas dimensões em tamanho nanométrico, ou seja, em escala 1/1.000.000.000, ou um bilionésimo do metro $(1 \mathrm{~nm}=$ $\left.10^{-9} \mathrm{~m}\right)$. Nessa escala de tamanho, os materiais apresentam novas propriedades, antes não observadas quando em tamanho micro ou macroscópico, por exemplo, a tolerância à temperatura, a variedade de cores, as alterações da reatividade química e a condutividade elétrica. ${ }^{3}$

Devido ao aumento da razão entre a área e o volume do nanomaterial, os efeitos de superfície se tornam mais importantes conferindo, a esses materiais, características especificas para determinadas aplicações; por exemplo, um material magnético tal como o ferro pode não se comportar como um ímã ao ser preparado sob a forma de nanopartículas, com tamanho da ordem de $10 \mathrm{~nm}$. Por outro lado, as nanopartículas esféricas de sílica presentes em um material, apesar de incolores, ao assumirem arranjos cristalinos bem empacotados podem difratar a luz visível tornando-se um material colorido. ${ }^{11,15}$

A essência da nanotecnologia consiste na habilidade de se trabalhar em nível atômico, molecular e macromolecular a fim de criar materiais, dispositivos e sistemas com propriedades e aplicações fundamentalmente novas. Os blocos de construção são os átomos e moléculas, ou um conjunto deles tais como nanopartículas, nanocamadas, nanofios ou nanotubos. Dessa forma, a nanotecnologia permite ao homem alcançar escalas além da sua limitação natural de tamanho e trabalhar diretamente na construção dos blocos de matéria. Esta escala está situada entre o comportamento de um átomo e o comportamento do volume do sólido, isto é, entre uma fração de nanômetro e cerca de $100 \mathrm{~nm}$, na qual são construídos os blocos básicos e em que as propriedades fundamentais são definidas e ajustadas em função do tamanho, forma e padrão do nanomaterial. O modo pelo qual a matéria é organizada, em estruturas maiores, também desempenha um papel essencial nas características e propriedades do sólido final. Dessa forma, se objetiva alcançar o controle em nível de nanoescala e na integração para obter escalas maiores. A habilidade para rearrumar a matéria em nanoescala é potencialmente um método econômico para obter funcionalidade, visando a um produto com alto valor agregado. A matéria pode ser rearrumada nessa escala através de interações fracas, tais como dipolo eletrostático, ligações de hidrogênio, forças de van der Waals, interações hidrofóbicas ou hidrofílicas, aglomeração fluídica e outras formas de agregação. Um exemplo dessa arrumação é a auto-agregação induzida, em que o arranjo das moléculas é conduzido sob controle, através de um campo magnético externo, um campo elétrico, um agente direcionador ou outros meios. ${ }^{1,2}$

A funcionalidade, uma das características mais importantes dos nanomateriais que permite sua extensa faixa de aplicações, é a sua capacidade de executar funções específicas. $\mathrm{O}$ termo funcionalização, comum em nanotecnologia, refere-se à execução de algumas funções químicas ou biológicas, através da projeção e manipulação desses materiais, de forma controlada e pré-determinada. ${ }^{11} \mathrm{~A}$ funcionalização de nanopartículas de ouro com biopolímeros, por exemplo, é empregada na construção de biossensores para a detecção de ácidos nucléicos e proteínas. ${ }^{16}$ Outro exemplo é a funcionalização dessas partículas com alcanotióis e amidoferrocenilalcanotiol, que permite a identificação de grupos tais como as espécies $\mathrm{H}_{2} \mathrm{PO}_{4}^{-}$e $\mathrm{HSO}_{4}^{-}$, em solução. ${ }^{7}$

Nos últimos anos, foram obtidas nanopartículas e nanocamadas com diferentes funções, tubos e fios de vários materiais, dispositivos moleculares tridimensionais, materiais para a substituição de tecidos vivos e novas ferramentas tais como pinças nanomecânicas. Também foram fabricados dispositivos ultra-pequenos, incluindo dispositivos eletrônicos moleculares, nanobiomotores e sistemas nanoeletromecânicos. Além disso, foram preparados compósitos nanoestruturados, produtos químicos e bioestruturas e foram desenvolvidas novas rotas de síntese de drogas e novos métodos de transporte através do corpo humano. Foram, ainda, desenvolvidos novos processos de preparação dos nanomateriais, incluindo a auto-aglomeração induzida e a fabricação de materiais com precisão atômica. Os principais aspectos científicos se referem à descoberta de novos fenômenos em nanoescala; de novos métodos de medidas e modelagem de um grande número de nano-objetos; do entendimento da relação entre a nanoestrutura e a aplicação do material; da manipulação com precisão atômica e molecular, da agregação e conexão em nanoescala; do entendimento da moderna biologia e do sinergismo com a informação tecnológica. Além disso, foi demonstrado o comportamento quântico à temperatura ambiente e o confinamento quântico dos nanomateriais. ${ }^{1}$

Os materiais funcionalizados como os nanocristais, as nanopartículas, os nanofios, as nanofitas, os nanotubos e os nanocompósitos possuem potencial de aplicação em catálise, na síntese de colóides, em processos fotoquímicos, no desenvolvimento de sensores e dispositivos eletrônicos, em aplicações médicas, na obtenção de novos fármacos e no controle ambiental. ${ }^{15,16}$ Entre essas nanoestruturas, as nanopartículas de ouro e os nanotubos de carbono são considerados como uma das mais promissoras aplicações da nanotecnologia em catálise. ${ }^{8}$

\section{PREPARAÇÃO DE MATERIAIS EM ESCALA NANOMÉTRICA}

O processo de obtenção de nanomateriais consta na literatura desde 1857, quando Faraday relatou a síntese do ouro coloidal. A 
partir desta época, e até os dias atuais, vários métodos de preparação de nanopartículas metálicas empregadas como catalisadores vêm sendo desenvolvidos. ${ }^{17}$ Em geral, eles são métodos químicos, em especial aqueles baseados em fenômenos de auto-montagem e autoorganização e consideram aspectos como a qualidade, a rapidez e o custo da preparação.

Do ponto de vista tecnológico, os nanomateriais podem ser preparados segundo uma abordagem bottom-up ("de baixo para cima"), construindo os materiais a partir de átomos ou moléculas individuais ou através do procedimento top-down ("de cima para baixo"), por meio da ruptura de uma porção maior do material em nanopartículas, fazendo-se uso das técnicas de litografia.$^{18}$ Essas técnicas, geralmente, utilizam um feixe eletrônico para fabricar estruturas nas três dimensões, originando os pontos quânticos. $\mathrm{Na}$ abordagem "de cima para baixo" um material nanométrico pode ser obtido a partir da técnica de evaporação-condensação do material de interesse sobre uma superfície por várias etapas de corrosão química seletiva. Um exemplo é a evaporação de ouro e paládio sobre mica. ${ }^{19}$

No procedimento de "baixo para cima", os átomos podem ser depositados sobre uma superfície regular e se auto-agruparem sobre a superfície, formando estruturas nanométricas com tamanho e características bem definidos. Em 1990, Eigler e Schweizer construíram o logotipo da empresa americana IBM, utilizando um microscópio eletrônico de tunelamento com sonda de varredura, através do arranjo preciso 35 átomos de xenônio sobre uma superfície de níquel. Desde o ano 2000, as sondas dos microscópios de tunelamento assumiram a função de desenhar e escrever nanoestruturas, através do método conhecido como nanolitografia. ${ }^{20}$

Do ponto de vista catalítico, a síntese de nanomateriais visa ao desenvolvimento de nanopartículas em um estado altamente disperso, com diâmetro de partículas menores que $10 \mathrm{~nm}$. Os processos de preparação envolvem geralmente o uso de agentes redutores, tais como citrato de sódio, boridreto de sódio, hidrazinas, formaldeídos, hidroxilaminas, álcoois saturados e insaturados e açúcares. ${ }^{21,22}$ Dentre os açúcares, o ácido ascórbico produz as nanopartículas mais estáveis e mais dispersas no suporte, devido à sua forte ação redutora. ${ }^{22}$

O controle rigoroso de variáveis, tais como $\mathrm{pH}$ do meio reacional, temperatura de calcinação e a dispersão das espécies químicas de interesse, é considerado crítico, especialmente quando se considera o controle do tamanho de partícula. ${ }^{23}$ Nesse contexto, tem-se investigado como os diferentes métodos de preparação dos catalisadores, a natureza do suporte e a interação metal-suporte afetam o tamanho e a forma das nanopartículas, visando a aumentar e estabilizar a atividade catalítica. ${ }^{24}$ Os métodos mais empregados na preparação de nanopartículas metálicas são o processo sol-gel, o método de deposição-precipitação, o método de co-precipitação, o método de impregnação e o método de deposição química a vapor.

O método sol-gel é baseado na hidrólise e condensação de precursores moleculares, tais como alcóxidos e íons hidroxilatos metálicos em solução aquosa. Esse processo constitui um importante meio de preparação de materiais baseados em óxidos nanoestruturados, cerâmicas nanoporosas e materiais híbridos, em que espécies orgânicas ou biológicas instáveis podem ser adicionadas a óxidos refratários ${ }^{25} \mathrm{Du}-$ rante a formação do gel, é possível reter moléculas estranhas em sua estrutura. Em particular, biomoléculas e microrganismos podem ser inseridos na matriz sol-gel, permitindo o desenvolvimento de novos nanocompósitos bioativos empregados como substâncias inibidoras de atividade parasitológica. Dessa forma, são obtidas nanopartículas com tamanho e dispersão adequados em função das diferentes estruturas, funcionalidade e reatividade do precursor utilizado. ${ }^{26}$

No processo de coprecipitação um hidróxido ou carbonato, tanto do suporte como do metal, é obtido através da adição simultânea das soluções dos sais precursores. Em seguida, o precipitado obtido é lavado, seco e calcinado. Este método é frequentemente usado para preparar nanopartículas de metais da primeira série de transição nos grupos 4 a 12 da tabela periódica. Em especial, nanopartículas de ouro suportadas em óxidos de cério, ferro, cobalto e manganês são preparadas por esse método. ${ }^{27}$

Considerado um dos métodos mais tradicionais de preparação de catalisadores, a impregnação é amplamente empregada na obtenção de catalisadores suportados. Recentemente, ele tem sido usado também na obtenção de nanopartículas de ouro e de platina. ${ }^{27,28}$ Neste método, uma solução de um sal do metal é mantida em contato com o suporte que pode estar sob a forma de um filme, um pó ou uma pastilha, durante um período previamente determinado. Em seguida, a suspensão é filtrada, seca e calcinada. Este método é bastante utilizado para preparar sistemas contendo metais nobres suportados em materiais mesoporosos. ${ }^{29}$

O método de deposição a vapor pode ser dividido em duas classes principais: a deposição física e a deposição química a vapor. A deposição física a vapor envolve processos físicos de formação de nanocristais, como por exemplo, a eletrodeposição de nanopartículas empregando microscopia Raman. ${ }^{30}$ Por outro lado, a deposição química a vapor consiste na passagem de uma corrente de vapor do precursor metálico volátil, sobre um suporte com elevada área superficial especifica. O composto, sob a forma de vapor, reage quimicamente com a superfície do suporte formando as espécies ativas. Este método é empregado na preparação de nanopartículas de metais nobres sobre vários suportes, incluindo a alumina, a titânia, a sílica e a MCM- $41 .{ }^{29,30}$

\section{NANOCIÊNCIA, NANOTECNOLOGIA E CATÁLISE HETEROGÊNEA}

É conhecido, há muitos anos, que o comprimento de escala de importância em catálise heterogênea é de escala nanométrica ou menor; este é o tamanho do cristal de um metal nobre bem disperso, ou da cavidade ou canal de uma zeólita ou, ainda, o tamanho do ligante de um composto de coordenação ou o centro ativo de uma enzima. ${ }^{31}$ Dessa forma, a catálise heterogênea é provavelmente a área mais antiga da nanotecnologia. Os catalisadores metálicos, desde há muito tempo, são usualmente preparados como nanopartículas, dispersas em superfícies de materiais de áreas superficiais específicas elevadas e estáveis, tais como alumina, sílica ou carvão ativado..$^{32-37}$ Os catalisadores modernos de elevado desempenho são atualmente projetados para considerar a significativa contribuição do suporte e cuidadosamente sustentar partículas metálicas de dimensões nanométricas. É também conhecido que a atividade catalítica de partículas metálicas suportadas é fortemente dependente do seu tamanho e forma e, portanto, os catalisadores nanoestruturados são altamente ativos, uma vez que a maioria da superfície da partícula pode estar disponível para a reação. ${ }^{37}$ Espera-se que esses sistemas possam ser otimizados com os princípios da nanociência e os recursos da nanotecnologia, através do controle dos arranjos superficiais atômicos, assim como da otimização de estruturas e densidade dos sítios ativos. Isto incluiria a habilidade de manipular o depósito de átomos em locais específicos, para promover uma velocidade específica de reações sensíveis à estrutura. ${ }^{38}$

A nanociência e a nanotecnologia podem ser mais relevantes nos casos em que a reação é sensível à estrutura, ou seja, nos casos em que a velocidade de reação por átomo superficial exposto (turnover frequency, TOF) depende da identidade dos planos cristalinos expostos, ou se eles são lisos ou rugosos, como ocorre com as reações de oxidação. Estas reações ocorrem, em geral, mais rapidamente sobre superfícies rugosas uma vez que, sobre a superfície de óxidos metálicos, apenas uma pequena fração de sítios superficiais, os sítios 
defeituosos, é responsável pela adsorção do oxigênio. Dessa forma, há uma grande oportunidade para as nanopartículas de óxidos metálicos serem excelentes catalisadores, possuindo uma fração maior de extremidades, esquinas ou degraus nessa faixa de tamanho. Isto daria origem a velocidades mais altas de redução e oxidação das camadas superficiais. ${ }^{39}$

$\mathrm{O}$ avanço na nanociência pode também ajudar a aumentar o entendimento do arranjo das unidades básicas das zeólitas e do agente direcionador de estrutura durante a síntese e como eles conduzem à estrutura final. Ele pode permitir o projeto de zeólitas mais eficientes ou outros novos materiais que possuam propriedades desejadas similares. O rápido avanço na síntese de nanomateriais pode ainda permitir a incorporação do íon alumínio, em locais específicos das zeólitas. ${ }^{38}$

Entretanto, espera-se que a maior contribuição da nanociência e da nanotecnologia para a catálise deva advir da melhoria da seletividade dos catalisadores. A seletividade, isto é, a formação de um entre outros produtos termodinamicamente possíveis, é menos entendida que a atividade. Isto se deve a diversos fatores, que têm sido documentados ao longo do tempo, entre eles a estrutura do catalisador em escala atômica. ${ }^{4}$ Por exemplo, é conhecido que o bloqueio dos sítios catalíticos pelo enxofre, pela adição de sulfeto de hidrogênio à nafta, também ocorre em escala atômica, eliminando a hidrogenólise (reação indesejável) pelo envenenamento seletivo dos sítios ativos da reação. ${ }^{40}$ Por outro lado, em escala nanométrica, os catalisadores bifuncionais têm sido documentados como exercendo um papel importante na seletividade. ${ }^{34,41}$ Nesses sistemas, as moléculas reagentes sofrem transformações químicas para produzir intermediários, que irão se difundir para outros sítios, onde sofrem novos arranjos para formar o produto final que, então, dessorve. Nessas circunstâncias, a seletividade varia acentuadamente com a conversão, como ocorre na reação de Fischer-Tropsch que produz hidrocarbonetos de cadeia longa a partir de monóxido de carbono e hidrogênio. ${ }^{37,42}$ Existem outros fatores que afetam a seletividade nos catalisadores industriais de elevada área superficial específica. Por exemplo, a nanoarquitetura das zeólitas pode aumentar a seletividade pelo controle da velocidade de difusão dos reagentes e produtos de acordo com a forma das moléculas. ${ }^{43,44}$ Dessa maneira, no que se refere ao futuro da pesquisa no controle da seletividade das reações, existem algumas questões básicas, que devem ser atendidas: quantos átomos metálicos de catalisador são necessários para formar ou romper ligações químicas no caso do oxigênio, hidrogênio, nitrogênio, monóxido de carbono e outras moléculas mais complexas, em que a ruptura das ligações $\mathrm{C}-\mathrm{H}$ e C-C desempenha um papel importante; qual o papel da estrutura da superfície e da arquitetura em três dimensões do retículo cristalino das nanopartículas; qual o papel dos promotores e, qual o papel das reações secundárias que são provavelmente controladas por difusão. ${ }^{37}$ Kubo e Friedel estiveram entre os primeiros que discutiram o efeito da estrutura eletrônica dos nanoaglomerados metálicos, considerando que eles são similares às moléculas. ${ }^{45,46}$ Eles observaram que não existem efeitos de superfície entre as partículas contíguas, dependendo da relação superfície-volume e da forma das partículas, que também alteram o espaçamento entre os níveis eletrônicos de energia. Existem diferenças na estrutura eletrônica de pequenos aglomerados (clusters) metálicos dependendo da presença de números ímpares ou pares de elétrons. ${ }^{37}$ Os estudos de microscopia eletrônica mostraram que as nanopartículas são altamente ordenadas e ligadas por faces cristalinas com baixos valores de índice de Miller. ${ }^{46}$ Essa observação explica a grande similaridade no comportamento das superfícies de um monocristal e das nanopartículas. A síntese de nanopartículas metálicas, com faces cristalinas bem definidas, abre a possibilidade de utilizar os dados disponíveis das superfícies de monocristais. ${ }^{47}$ A reatividade das superfícies de monocristais pode ser usada como um guia na prepa- ração de nanopartículas metálicas, com faces cristalinas otimizadas, para produzir catalisadores heterogêneos altamente seletivos. Dessa maneira, pode-se evitar a diversidade inconveniente de sítios ativos com diferentes reatividades, que é uma das razões da seletividade mais baixa dos catalisadores heterogêneos, quando comparados às enzimas. Um outro aspecto a ser considerado é que as superfícies metálicas são reestruturadas quando as moléculas são quimissorvidas e, durante a reação, tanto os monocristais como as nanopartículas podem ser rapidamente reestruturadas e apresentarem estruturas de superfície muito similares. ${ }^{48} \mathrm{~A}$ diferença é que os monocristais, e na verdade os aglomerados de grande tamanho, se reestruturam apenas nas regiões superficiais, enquanto as nanopartículas pequenas podem se reestruturar como um todo. Pequenos aglomerados possuem partículas com maior mobilidade e podem se reestruturar mais rapidamente que os maiores, por causa dos números de coordenação mais baixos dos átomos metálicos. Nessas circunstâncias, várias configurações possuem valores similares de energia livre de formação. Além disso, o calor de adsorção exotérmico das moléculas desses agregados pode ser compensado pelo efeito endotérmico do enfraquecimento da ligação metal-metal, necessária à reorganização. A reestruturação é essencial para a ruptura da ligação dos reagentes e o rearranjo molecular e é parte essencial do ciclo catalítico. Esta é a razão pela qual a tecnologia dos catalisadores emprega nanoagregados em vez de partículas maiores. Os pesquisadores já empregam nanocatalisadores em estudos de seletividade e investigam a influência da forma e do tamanho no comportamento químico do catalisador. O principal obstáculo a ser superado é o desenvolvimento de métodos sintéticos reprodutíveis para a preparação de catalisadores nanoestruturados, em que os parâmetros de tamanho e forma possam ser variados de forma sistemática. ${ }^{37}$

Diversos laboratórios já conduziram a síntese de metais nanodispersos e nanoagregados de semicondutores com esse propósito. ${ }^{49} \mathrm{Um}$ exemplo é a obtenção de nanopartículas de platina, empregadas em reações de isomerização, desidrogenação e hidrogenação, em que foi possível controlar o tamanho preciso das nanopartículas, a estrutura e a estabilidade térmica e química do material..$^{34,50}$ Entretanto, apesar do notável sucesso na preparação desse e de outros materiais, não se desenvolveu ainda um método geral para a síntese de um dado aglomerado ou coloide, com propriedades pré-determinadas, tais como dimensões definidas. A síntese de nanoaglomerados bimetálicos é de particular interesse nos processos catalíticos. Além disso, é crítico avaliar a estrutura e a química dos catalisadores nanoestruturados, em nível molecular. Além da caracterização dos catalisadores modelo e das moléculas adsorvidas em ultra alto vácuo, se requer informações sobre as variações que ocorrem na superfície dos catalisadores in situ, ou seja, nas condições da reação, na interface sólido-gás e sólido-líquido. ${ }^{51}$

O aumento de investimento e atenção em nanociência e nanotecnologia representa uma oportunidade para o renascimento da ciência catalítica. Focando a necessidade de alcançar $100 \%$ de seletividade nos processos catalíticos, deve-se perseguir o entendimento dos ingredientes moleculares que controlam a seletividade. Novos métodos de preparação devem ser desenvolvidos e novos métodos de caracterização, sob as condições da reação, devem ser empregados e criados. A resolução espacial e o tempo de resolução são importantes fronteiras para a pesquisa nesse campo. ${ }^{37}$

\section{Propriedades dos nanocatalisadores}

O termo nanocatalisador não se aplica ao fenômeno da catálise, que intrinsecamente ocorre em nanoescala. Ele se refere às propriedades dos catalisadores, que podem variar em função do tamanho em nanoescala; tipicamente, os nanocatalisadores possuem pelo menos 
uma dimensão em nanoescala, externa ou internamente e sua atuação na reação depende criticamente do tamanho da partícula. ${ }^{52}$ As propriedades relacionadas ao tamanho nanométrico de partículas metálicas suportadas, por exemplo, afetam diretamente a atividade catalítica e se manifestam em uma escala de tamanho de algumas centenas de átomos, não podendo ser extrapoladas a partir das propriedades do sólido mássico.

A propriedade mais importante que influencia o desempenho dos catalisadores é a estrutura eletrônica. A Figura 1 mostra a evolução das energias de ligação dos elétrons $4 \mathrm{~s}$ e $3 \mathrm{~d}$ dos agregados de cobre em função do tamanho. ${ }^{53}$ Pode-se observar que a estrutura eletrônica, que é influenciada pelas bandas s e d, evolui de forma não monotônica em função do tamanho. De fato, ela depende do número exato de átomos no agregado. Quando os agregados, no entanto, alcançam um tamanho de 30 a 50 átomos, a estrutura eletrônica evolui suavemente em direção ao valor limite do sólido. Diversos pesquisadores mostraram que as propriedades químicas de pequenos agregados metálicos livres realmente evoluem de maneira discreta com o número exato de átomos. ${ }^{54,55} \mathrm{~A}$ mesma tendência foi observada com os agregados suportados. ${ }^{56}$

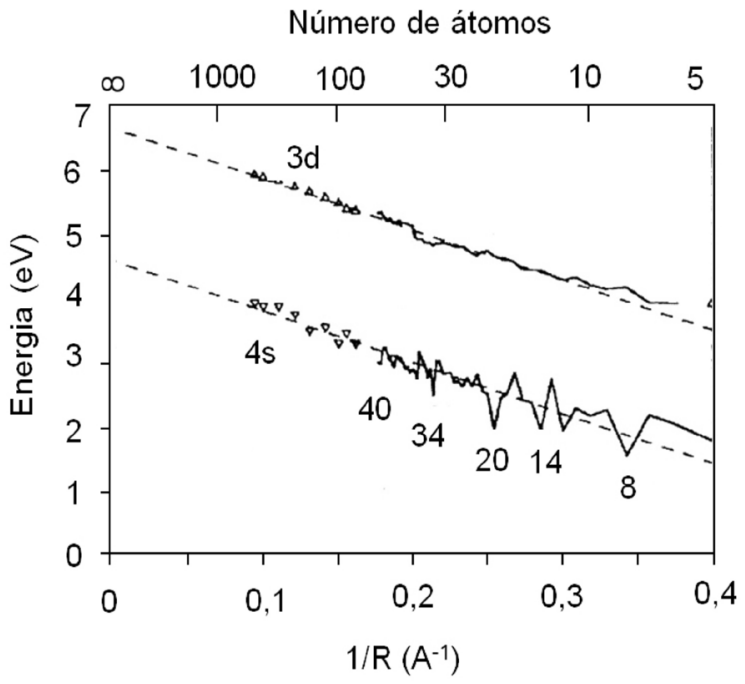

Figura 1. Evolução das propriedades eletrônicas de pequenos agregados de cobre em função do seu tamanho. Adaptada da ref. 53

Como a reatividade da oxidação do monóxido de carbono sobre agregados de platina mostra uma dependência similar, como uma consequiência direta da evolução das propriedades eletrônicas, poder-se-ia esperar que as propriedades catalíticas dos agregados metálicos fossem evoluir suavemente até cerca de cinqüenta átomos, podendo ser esses resultados extrapolados para o limite do sólido. Entretanto, isto não ocorre e, frequentemente, as propriedades catalíticas de nanopartículas metálicas suportadas não podem ser previstas a partir de experimentos com superfícies metálicas não nanométricas. ${ }^{57}$ De fato, as nanopartículas suportadas, que constituem a maioria dos catalisadores heterogêneos, possuem propriedades físicas que diferem daquelas do material não nanométrico. ${ }^{52}$ O exemplo mais marcante é apresentado pelo ouro, que é o metal mais nobre e, portanto, o menos reativo. Em tamanho nanométrico, entretanto, os átomos de ouro se transformam em catalisadores ativos em muitas reações. Essa especificidade em catálise, devido ao tamanho nanométrico, pode ser atribuída a várias razões. A primeira delas está relacionada ao fato das partículas pequenas (1-20 $\mathrm{nm}$ ) apresentarem estruturas cristalinas com faces bem definidas, constituídas por planos densos, que minimizam a energia superficial. Como a reatividade dos planos cristalinos depende fortemente da sua estrutura, as partículas metálicas de diferentes tamanhos irão apresentar diferentes proporções de faces, que podem reagir de formas completamente diferentes umas das outras. ${ }^{47}$ Esse efeito irá depender da percentagem das diferentes faces e das barreiras de difusão para as espécies adsorvidas se deslocarem de uma face a outra. ${ }^{58}$ Como observado por microscopia de tunelamento as extremidades de contato entre duas faces do cristal, e que correspondem a átomos em baixa coordenação, possuem densidades de estado locais diferentes em relação aos átomos em alta coordenação da face.$^{59}$ Dessa forma, a coordenação do átomo também influencia na ação catalítica. Esse efeito da extremidade se torna importante em partículas menores que $5 \mathrm{~nm}$, em que a razão entre os átomos nas extremidades e na superfície é elevada. ${ }^{5}$ Isto é mostrado na Figura 2 , que ilustra partículas modelo de ouro em diferentes suportes. ${ }^{60}$
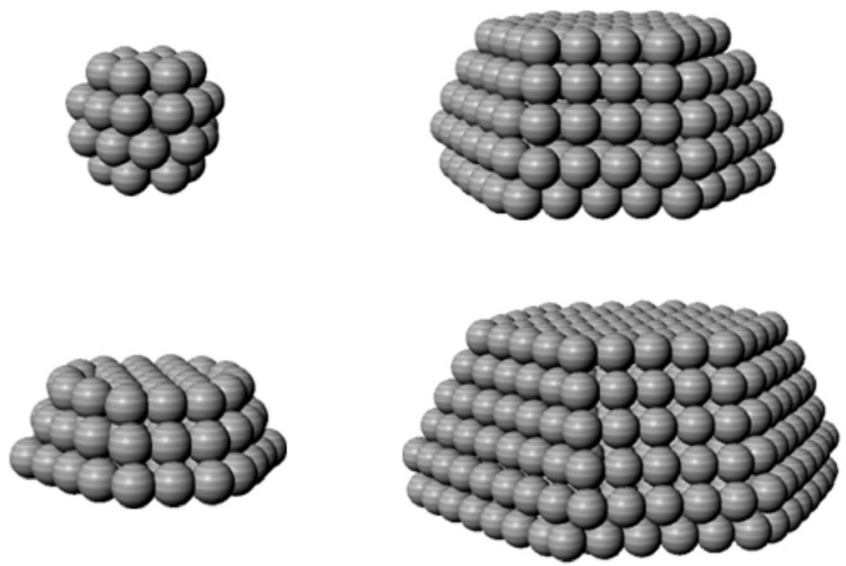

(a)

(b)

Figura 2. Exemplos de partículas modelo de ouro de catalisadores do tipo (a) $\mathrm{Au} / \mathrm{Al}_{2} \mathrm{O}_{3}$ e (b) $\mathrm{Au} / \mathrm{MgAl}_{2} \mathrm{O}_{4}$. As partículas em (a) são mais redondas que aquelas em (b) e possuem mais átomos nas extremidades em relação ao volume do agregado. Adaptado da ref. 60

Outras mudanças significativas ocorrem quando o tamanho das partículas diminui como exemplificado pelas nanopartículas de paládio suportadas nas faces (001) do sulfeto de molibdênio, esquematizado na Figura 3.52 Como essa partícula contém apenas duas camadas de átomos de altura, pode-se concluir que ela contém vinte e sete átomos, exatamente vinte na primeira camada e sete na segunda. Comparada a uma partícula maior (aproximadamente quatrocentos átomos), essa nanopartícula apresenta sítios muito abertos; um deles é o chamado sítio $\mathrm{B}_{5}$, previsto anteriormente como um sítio muito ativo, responsável pelo forte efeito de tamanho em catálise. ${ }^{61}$ Pode-se observar, pela Figura 3, que os átomos de enxofre do substrato em volta do agregado de paládio parecem se situar acima do plano do substrato. De fato, esse é um efeito aparente devido a modificações eletrônicas dos átomos do substrato pelos átomos metálicos. Por outro lado, as estruturas eletrônicas dos átomos metálicos na interface são também modificadas pelo substrato, que possui uma forte influência sobre a atividade catalítica. Em agregados metálicos muito pequenos, todos os átomos podem ser modificados pelo substrato, sobretudo em defeitos que resultam em agregados carregados, que modificam drasticamente as propriedades catalíticas. ${ }^{62}$

Diversas propriedades físicas das partículas são modificadas, à medida que seu tamanho vai diminuindo até à escala nanométrica, resultando em mudanças na atividade catalítica. A energia de superfície das nanopartículas, por exemplo, difere daquela dos sólidos. De modo simplificado, pode-se considerar que a energia de superfície corresponde ao número de ligações dos átomos su- 


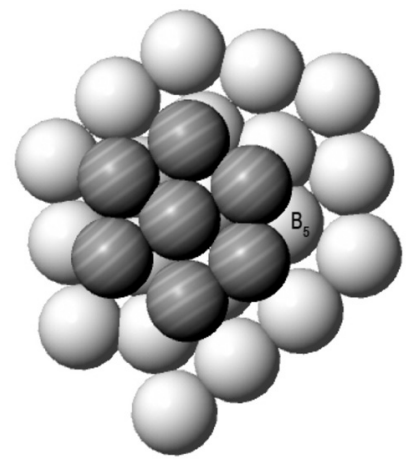

Figura 3. Esquema de um agregado metálico de paládio suportado em sulfeto de molibdênio, mostrando o sítio $B_{5}$. Adaptado da ref. 53

perficiais que foram rompidas, relativamente ao sólido. Diversos cálculos mostraram que as energias de superfície são mais elevadas em nanopartículas na faixa de 2 a $3 \mathrm{~nm}$. Por sua vez, a tensão na superfície possui um efeito direto sobre os parâmetros de rede das nanopartículas. Essa tensão induz uma pressão em direção ao núcleo da nanopartícula, que provoca uma contração da rede, observando-se uma diminuição do parâmetro de rede com o aumento do raio das partículas. Essa contração tem sido observada com muitas partículas e é geralmente da ordem de alguns por cento. Quando as partículas estão em epitaxia com um suporte cristalino, a rede das pequenas partículas pode ser acomodada na rede do substrato. Se o parâmetro de rede do suporte é maior que aqueles das nanopartículas, sua rede pode ser expandida. ${ }^{5}$ Entretanto quando o tamanho das partículas aumenta, elas progressivamente recuperam o parâmetro de rede do sólido pela introdução de deslocamentos. ${ }^{52}$

A forma das partículas também é afetada à medida que ela vai atingindo o tamanho nanométrico; por exemplo, um cristal com estrutura cúbica de corpo centrado apresenta a forma de um octaedro truncado, exibindo faces hexagonal (111) e quadrada (100), que são os planos de energia de superfície mais baixas. Entretanto, partículas com 2 a $3 \mathrm{~nm}$ possuem energia de superfície mais elevadas e a fração de átomos nas extremidades aumenta. Considerando um modelo simples, Marks mostrou que a face (100) desaparece em partículas de pequeno tamanho e a forma de equilíbrio de uma partícula com estrutura cúbica de face centrada se torna um octaedro. ${ }^{63}$ Outro aspecto a ser considerado é que, em tamanhos muito pequenos, a estrutura esperada do sólido é raramente a mais estável. É conhecido que a estrutura mais estável de um agregado metálico de treze átomos é um icosaedro, ${ }^{64}$ que pode ser estável até tamanhos relativamente grandes; ele não se transforma diretamente na estrutura esperada do sólido, mas sofre uma transição passando por uma estrutura chamada decaedro de Marks, que consiste de um decaedro truncado. ${ }^{52}$

Outra propriedade física que depende fortemente do tamanho é o ponto de fusão. É conhecido, desde há muito tempo, que o ponto de fusão de um cristal decresce com o inverso do seu raio. Esse fenômeno é devido ao aumento da fração de átomos na superfície. ${ }^{52}$

A estrutura de bandas eletrônicas também é alterada à medida que o tamanho da partícula se aproxima do tamanho nanométrico. As partículas metálicas maiores que cem átomos apresentam a banda eletrônica esperada do sólido; entretanto, quando a proporção de átomos da superfície se torna não desprezível aparecem muitas diferenças na estrutura de bandas; a largura da banda de valência é diminuída e seu centro de gravidade é deslocado em direção ao nível de Fermi ${ }^{65}$ Essa evolução é uma conseqüência da redução do número de coordenação, que é equivalente a um aumento na localização dos elétrons de valência. Isto se torna mais dramático quando se considera a densidade local de estados nos sítios de baixa coordenação, tais como os átomos nos vértices e arestas. ${ }^{52}$
Aplicações das nanopartículas de ouro em processos catalíticos

Os catalisadores de ouro constituem os exemplos mais marcantes e representativos do efeito do tamanho da partícula sobre o desempenho catalítico. O ouro era considerado um material cataliticamente inerte até 1980, quando Haruta e col. mostraram que partículas desse metal com tamanho inferior a $10 \mathrm{~nm}$ eram ativas em reações de oxidação do monóxido de carbono, em temperaturas tão baixas como $0{ }^{\circ} \mathrm{C} .{ }^{66}$ Os trabalhos anteriores, revisados por Wachs e Schwank, indicavam que o ouro era cataliticamente inferior aos outros metais nobres, embora ele apresentasse algum potencial, com respeito à seletividade, em diversas reações. ${ }^{67,68}$ Devido ao seu ponto de fusão $\left(1063{ }^{\circ} \mathrm{C}\right)$ ser muito mais baixo que aquele do paládio $\left(1550{ }^{\circ} \mathrm{C}\right) \mathrm{e}$ da platina $\left(1769{ }^{\circ} \mathrm{C}\right)$, quando se empregava o método convencional de impregnação, era difícil depositar ouro sobre óxidos metálicos, com dispersões tão altas quanto aquelas obtidas com os metais do grupo da platina. ${ }^{69}$ Essa situação mudou, entretanto, quando foi possível depositar o ouro como nanopartículas sobre óxidos metálicos, através de métodos de coprecipitação e deposição-precipitação. A partir dessa época, um grande número de trabalhos foi desenvolvido, com o objetivo de obter nanopartículas de ouro e diversos artigos de revisão foram publicados. ${ }^{70-72}$ Seguindo a descoberta de Haruta e colaboradores, ${ }^{66}$ esses estudos mostraram que o ouro é cataliticamente ativo em muitas outras reações tais como a epoxidação do propileno, ${ }^{73}$ a síntese do peróxido de hidrogênio e do cloreto de vinila, ${ }^{74,75} \mathrm{a}$ oxidação seletiva de álcoois, ${ }^{76}$ as reações de acoplamento de ligações carbono-carbono e outras. ${ }^{77,78}$ Paralelamente, o baixo preço do ouro no mercado internacional (o ouro custa US\$ 7/g enquanto a platina e o paládio custam US\$14/g) e sua cotação mais baixa na bolsa de valores, aliado à sua maior disponibilidade comercial, contribuíram para o emprego de catalisadores contendo ouro em vários processos catalíticos. $^{79}$

As descobertas nesse campo são contínuas e avançam com velocidade surpreendente, mas existem comparativamente poucas publicações referentes ao estudo de catalisadores de ouro suportado em seu estado ativo, no meio reacional. A maioria dos estudos focaliza a oxidação do monóxido de carbono, devido ao seu potencial de aplicação prática, por exemplo, na purificação de hidrogênio para células a combustível em automóveis e porque o monóxido de carbono é adequado como um sistema modelo para o entendimento fundamental das estruturas superficiais dos catalisadores. ${ }^{80}$

A literatura reflete um consenso de que o método de preparação e a escolha do suporte influenciam, de modo significativo, na atividade das partículas de ouro suportadas na oxidação do monóxido de carbono e que essa atividade é afetada pela presença de traços de água e de outros componentes, tais como os haletos. ${ }^{81}$

Entretanto, as hipóteses sobre a natureza dos sítios ativos, nos catalisadores de ouro suportados, são variadas e contraditórias. Diversas explicações têm sido propostas para explicar a elevada atividade desse metal. Embora exista um consenso de que a atividade do ouro aumenta com a diminuição do tamanho da partícula abaixo de $5 \mathrm{~nm}$ (e especialmente abaixo de $3 \mathrm{~nm}$ ), ${ }^{65,82-85} \mathrm{O}$ aumento da atividade catalítica é atribuído a diferentes espécies, tais como partículas metálicas muito pequenas, ${ }^{83}$ conjuntos de sítios metálicos e parcialmente oxidados, ${ }^{86}$ agregados de ouro aniônicos, ${ }^{87}$ catiônicos ou zero ou átomos de ouro na superfície das nanopartículas e, especificamente, a átomos de ouro na interface ouro-suporte, assim como a átomos de ouro em baixa coordenação. ${ }^{88-91}$ Distinguir entre essas diversas possibilidades é um desafio, porque as estruturas das espécies suportadas de ouro são complexas, não uniformes e tão pequenas que são difíceis de serem adequadamente caracterizadas. Um catalisador típico de ouro suportado consiste de nanopartículas de ouro de vários tamanhos e formas, dispersas sobre um suporte amorfo, usualmente um óxido metálico 
de elevada área superficial específica. Numa tentativa de superar a complexidade estrutural desses sistemas, alguns pesquisadores prepararam sistemas estruturalmente mais simples que os catalisadores típicos, com nanoagregados de tamanho limitado ou controlado. Por exemplo, foram estudados catalisadores com tamanhos limitados dos nanoagregados ${ }^{87}$ e sistemas com suportes com superfícies planares, incluindo um monocristal para facilitar as investigações em ultra alto vácuo. ${ }^{83,85}$ Entretanto esse último sistema, chamado de catalisador modelo, conduz a conclusões limitadas devido à inexistência de algumas características típicas dos sistemas reais como, por exemplo, a presença de grupos hidroxila e/ou água no suporte..$^{80}$

A multiplicidade de sítios ativos do ouro em um catalisador e sua ativação, sob diferentes condições, observada em diferentes trabalhos, ${ }^{52,53}$ pode parcialmente explicar a discrepância na natureza dos sítios ativos de ouro descritos na literatura. Possivelmente, os diversos grupos de pesquisa trabalharam sob diferentes condições, ativando diferentes sítios no mesmo catalisador. Dessa forma, a questão que surge não é inferir sobre a natureza dos sítios, mas que sítios são ativados em um dado catalisador. Portanto, em alguns casos, provavelmente os resultados dos diferentes grupos não se contradizem, mas se complementam.

Em todos os casos, entretanto, admite-se que as propriedades catalíticas do ouro são oriundas do seu tamanho nanométrico. À medida que as partículas se tornam cada vez menores, surgem novos efeitos. Alguns desses fenômenos estão relacionados à transição do comportamento do estado sólido para as propriedades moleculares e atômicas, conhecidas como nanoefeitos reais. Por exemplo, nas partículas menores a estrutura eletrônica de bandas varia de modo significativo com o tamanho da partícula e materiais tais como o ouro, que são em geral quimicamente inertes, se tornam cataliticamente ativos. Os cálculos da teoria de densidade funcional de várias configurações do ouro mostraram que a interação entre as moléculas de monóxido de carbono e de oxigênio depende no número de coordenação dos átomos de ouro. ${ }^{54-57} \mathrm{Se}$ o metal possui um número de coordenação elevado (superior a oito), nas faces (100) e (111) do ouro mássico, essas moléculas são repelidas e, portanto, esses átomos não serão cataliticamente ativos. Entretanto, quando o número de coordenação é baixo, ocorre a adsorção das moléculas e então o catalisador é ativo, indicando que o metal ativo exige a presença de átomos de ouro em baixos estados de oxidação. ${ }^{54,55}$ De fato, a atividade catalítica pode variar em várias ordens de grandeza devido ao efeito do número de coordenação $\mathrm{Au}-\mathrm{Au}$, que torna esse efeito dominante e crucial nos catalisadores de ouro ${ }^{54}$ Outros efeitos, incluindo tensões, efeitos induzidos pelo suporte, efeitos eletrônicos e carga dos átomos de ouro, podem também contribuir para a atividade catalítica das partículas de ouro, mas a sua influência é significativamente menor. Vários estudos, usando espectroscopia na região do infravermelho, forneceram fortes evidências experimentais da correlação entre o número de coordenação do ouro calculado e sua interação com moléculas de monóxido de dióxido de carbono, demonstrando que essa molécula é adsorvida nos sítios das arestas e vértices das partículas de ouro, independente do tamanho e espessura nas partículas metálicas. ${ }^{47,92}$ Nos catalisadores de ouro suportado, as arestas e os vértices das nanopartículas possuem número de coordenação inferior a oito e, portanto, os sítios ativos provavelmente contêm muitos desses átomos. Consequentemente, a atividade global do catalisador deve ser determinada principalmente pelo número de átomos localizados nessas posições, em um dado catalisador. ${ }^{61}$

Atualmente, as nanopartículas de ouro são empregadas em várias reações catalíticas entre as quais merecem destaque a oxidação preferencial do monóxido de carbono, a oxidação de hidrocarbonetos, a redução de óxidos de nitrogênio com hidrocarbonetos, monóxido de carbono ou hidrogênio, a epoxidação do estireno, a oxidação do etanol, a hidrogenação de hidrocarbonetos, a oxidação e decomposição de aminas e compostos orgânicos halogenados e a reação de deslocamento de monóxido de carbono com vapor d’água. ${ }^{93}$

A reação de deslocamento de monóxido de carbono com vapor d'água (WGSR, Water Gas Shift Reaction) é uma etapa importante na produção comercial de hidrogênio de elevada pureza, uma vez que as células a combustível de membrana protônica (PEM) são extremamente sensíveis à contaminação por monóxido de carbono. ${ }^{94}$ Mesmo em níveis de $1 \%$, esse composto causa o envenenamento do ânodo de platina, sob as condições de operação normal das células. Dessa forma, tem havido um considerável esforço para reduzir a níveis inferiores a 10 ppm, o teor de monóxido de carbono nesses sistemas. ${ }^{95}$ Neste caso, diversos suportes foram empregados, tais como óxido de alumínio, óxido de zircônio e óxido de titânio, óxido de cério e óxido de zircônio; entretanto, os dois últimos suportes produziram os catalisadores mais promissores e, por isso, têm sido os mais extensivamente investigados..$^{29,96}$

O elevado potencial do ouro como catalisador em reações de oxidação do etanol foi investigado por diversos pesquisadores, ${ }^{29,96,97}$ incluindo Sheng e colaboradores, ${ }^{98}$ que empregaram nanopartículas de ouro suportadas em óxido de cério. Por outro lado, Mellor e colaboradores prepararam sistemas catalíticos contendo óxido de cobalto promovido por aglomerados de átomos de ouro suportados em óxidos mistos de zircônia-céria, que foram empregados como componentes dos catalisadores automotivos de três vias (three-way). ${ }^{99}$ Estes catalisadores apresentaram boa estabilidade operando a $500{ }^{\circ} \mathrm{C}$, durante um período de $157 \mathrm{~h}$.

As possibilidades de emprego dos nanocatalisadores de ouro na redução de óxidos de nitrogênio também foram avaliadas por vários pesquisadores. ${ }^{100,101}$ Entre eles, Ueda e colaboradores prepararam catalisadores de ouro suportados, por métodos de coprecipitação e precipitação-deposição, obtendo sistemas com partículas de pequeno tamanho (3-5 nm), que conferiram ao catalisador elevada atividade na redução do monóxido de nitrogênio com propano, em presença de oxigênio. ${ }^{102}$

O emprego de catalisadores contendo nanopartículas de ouro sobre suportes mesoporosos constitui outra importante aplicação desses sistemas em catálise, como investigado por diversos pesquisadores. ${ }^{103-105}$ Por exemplo, Sobczak e colaboradores prepararam materiais mesoporosos do tipo MCM-41, contendo nanopartículas de ouro com diferentes tamanhos e observaram que esses sistemas eram promissores para a redução catalítica seletiva de óxido nítrico. ${ }^{105}$ Por outro lado, Yin e colaboradores utilizaram alumina mesoporosa como suporte de nanopartículas de ouro para obter catalisadores eficientes para a epoxidação do estireno. ${ }^{106}$

\section{Aplicações dos nanotubos de carbono em catálise}

As nanofibras de grafite (GNF, graphite nanofibers) ou nanofilamentos e nanotubos de carbono (CNT, carbon nanotubes), também têm sido consideradas como nanomateriais promissores para emprego como suportes ou como catalisadores. Eles têm sido largamente estudados, devido ao seu potencial de aplicação em diferentes áreas, tais como reforço de polímeros, estocagem de energia, eletrônica e catálise, como consequência das suas características específicas. ${ }^{107}$

Os nanotubos de carbono (Figura 4) são formados por camadas de átomos de carbono, em um arranjo hexagonal, originando pequenos cilindros com diâmetro de aproximadamente $1 \mathrm{~nm}$, que se enrolam para formar tubos longos, com comprimento de vários centímetros, unidos por átomos de carbono em arranjo pentagonal. ${ }^{108}$ As propriedades mecânicas e eletrônicas, exibidas por esses materiais, são determinadas pelo seu diâmetro e pela forma como os hexágonos de átomos de carbono se orientam em relação ao eixo do tubo. ${ }^{109}$ As 
diferentes formas de confinamento quântico conferem aos nanotubos de carbono propriedades de condutores ou semicondutores. Devido às suas estruturas quase-unidimensionais, a condução de corrente ocorre ao longo de toda a extensão do nanotubo sem necessidade de aquecimento. ${ }^{110}$

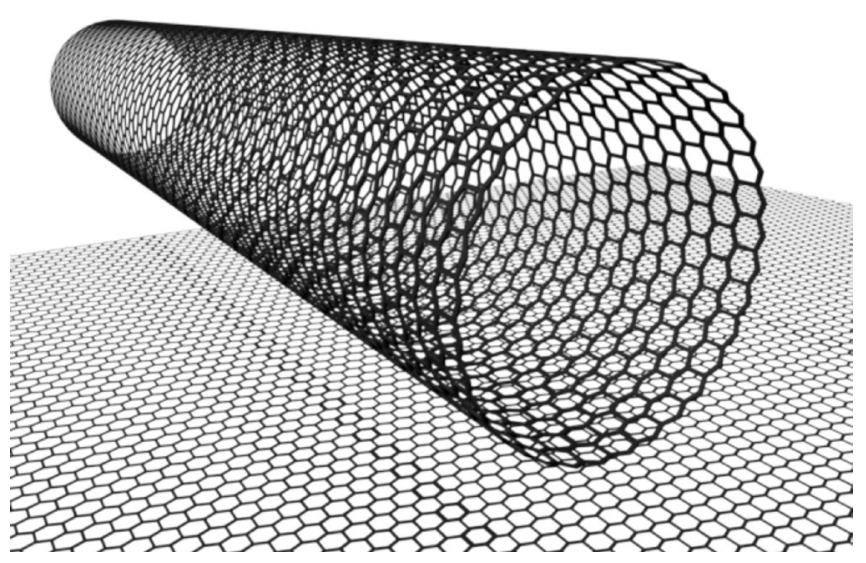

Figura 4. Esquema mostrando a formação de um nanotubo de carbono, a partir de uma camada, formada por anéis aromáticos, que se enrola entre si dando origem a uma estrutura tubular. Adaptado da ref. 108

Os nanotubos de carbono podem ser essencialmente divididos em duas categorias: nanotubos de uma parede, SWNT (single-walls nanotubes) e nanotubos de paredes múltiplas, MWNT (multi-walls nanotubes), como mostrado na Figura 5. Idealmente, um nanotubo de uma parede é formado por uma folha perfeita de grafeno, isto é, por uma camada poliaromática monoatômica constituída por um arranjo hexagonal de átomos de carbono com hibridização $\mathrm{sp}^{2}$, similares àqueles que formam a grafite, enrolados formando um cilindro e fechados pelas extremidades (semi-fulerenos). O diâmetro interno dessas estruturas pode variar entre 0,4 e $2,5 \mathrm{~nm}$ e o comprimento varia de alguns micra a vários milímetros. Os nanotubos de paredes múltiplas podem ser considerados como nanotubos de uma parede concêntricos com diâmetros decrescentes dispostos de modo coaxial. O número de paredes pode variar de duas (nanotubos de paredes duplas) a várias centenas, de modo que o diâmetro externo pode alcançar $100 \mathrm{~nm}$. As paredes concêntricas estão regularmente espaçadas por $0,34 \mathrm{~nm}$, de modo similar à distância entre os planos de grafeno evidenciadas em materiais grafíticos. As partículas metálicas, oriundas do processo de preparação desses materiais, podem se situar na cavidade interna do MWNT. A principal diferença entre nanotubos e nanofibras (GNF, graphite nanofibers) consiste na ausência de cavidade interna no último caso. As nanofibras podem ser de diferentes tipos, em função da disposição dos planos de grafeno: em forma de fita (GNF-R, ribbon-like $G N F$ ), em que as camadas de grafeno são paralelas ao eixo de crescimento; em forma de plaquetas (GNF-P, plaquets-like), em que as camadas de grafenos são perpendiculares ao eixo de crescimento e, em forma de espinha (GNF-H, herringbone nanofibers), que possuem camadas empacotadas obliquamente em relação ao eixo de crescimento. Os diâmetros das nanofibras de carbono são, em geral, maiores que aqueles apresentados pelos nanotubos e podem facilmente alcançar $500 \mathrm{~nm} .{ }^{107}$

O grande potencial do emprego de nanotubos e nanofibras de carbono, como suportes e como catalisadores, se deve às suas propriedades eletrônicas, adsortivas, mecânicas e térmicas. Numerosos estudos foram conduzidos abordando as propriedades eletrônicas dos nanotubos de carbono, enquanto as nanofibras são frequentemente

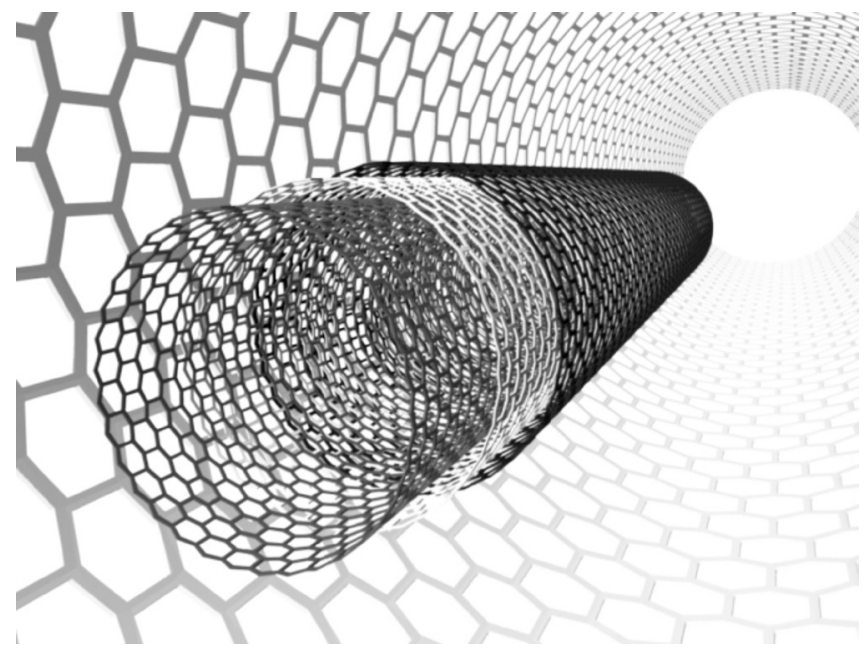

Figura 5. Esquema mostrando um nanotubo de paredes múltiplas

consideradas como substratos condutores, que podem exercer perturbações eletrônicas similares àquelas da grafite. ${ }^{111,112}$ No caso dos nanotubos de uma parede, diversos estudos mostraram que eles se comportam como fios quânticos puros (sistemas unidimensionais) onde os elétrons estão confinados ao longo do eixo do tubo. As propriedades eletrônicas são principalmente governadas pelo diâmetro do tubo e pela helicidade, definida como a forma pela qual a camada de grafeno é enrolada (braço de cadeira, zig-zag ou quiral); ${ }^{113}$ a forma em braço de cadeira apresenta características metálicas, enquanto a de zig-zag mostra um comportamento de semicondutor. Essas curvaturas das camadas de grafeno provocam grandes modificações nas propriedades eletrônicas, devido a alterações na nuvem eletrônica $\pi .{ }^{114}$ As propriedades eletrônicas dependem, também, da presença de defeitos tais como a presença de pentágonos, heptágonos, vacâncias ou impurezas, ${ }^{115}$ que causam desvios nas propriedades eletrônicas, em relação aos valores calculados. Além disso, os métodos de preparação não levam à produção de apenas um tipo de nanotubo de uma parede e o produto obtido, mesmo após as etapas de purificação, apresentam uma estrutura muito distante da estrutura esperada por considerações teóricas. ${ }^{107}$ Por outro lado, os nanotubos de paredes múltiplas se comportam como fibras de carbono: em temperaturas elevadas, sua condutividade elétrica pode ser descrita pelos modelos semi-clássicos usados para a grafite, enquanto em temperaturas baixas eles apresentam aspectos quânticos de transporte tridimensional. Neste caso, a predição das propriedades eletrônicas se torna ainda mais difícil, devido a dois fatores principais: a maneira como as camadas de grafeno se enrolam pode variar, ao longo das diferentes paredes de um tubo de um único tubo de paredes múltiplas e a maior complexidade da estrutura irá aumentar a possibilidade da ocorrência de defeitos. ${ }^{107}$

Quando usados nos processos catalíticos, esses suportes condutores apresentam diferenças óbvias com respeito ao carvão ativado; a principal delas é a interação com os metais de transição, uma vez que os sítios de ligação dependem da estrutura do suporte. ${ }^{116}$ Os estudos conduzidos com o níquel mostraram que os sítios de ancoragem mais estáveis variam consideravelmente entre a grafite e os nanotubos de uma parede, devido à diferente curvatura das superfícies onde as espécies ativas podem ser depositadas. A curvatura também afeta, de modo significativo, os valores de momento magnético dos átomos de níquel nas paredes dos nanotubos e a direção da transferência de carga entre o níquel e o carbono pode ser invertida. Portanto, deve-se considerar a possibilidade da existência de interações metal-suporte peculiares.

No que se refere às propriedades adsortivas, deve-se considerar a superfície interior e exterior dos nanotubos. Além disso, a curvatura das camadas de grafenos pode resultar em um calor de adsorção 
mais baixo, em relação àquele de uma camada plana. De fato, ao se enrolar sobre si mesma, a camada de grafenos provoca uma hibridização do orbital do carbono (configuração $\mathrm{sp}^{2}$ não planar) levando, portanto, a modificações da densidade $\pi$ dos da camada de grafeno. ${ }^{107}$ Muitos estudos destacaram a natureza porosa desses materiais. ${ }^{117}$ Os poros de um nanotubo de paredes múltiplas podem ser divididos em cavidades internas de pequenos diâmetros (na faixa de 3 a $6 \mathrm{~nm}$, em uma distribuição estreita de tamanhos) e em agregados de poros (na faixa de 20 a $40 \mathrm{~nm}$, em uma distribuição larga de tamanhos), formados pela interação de nanotubos de paredes múltiplas; este último desempenha um papel mais relevante na adsorção. Os diversos métodos experimentais têm mostrado a natureza microporosa dos nanotubos de uma parede e a natureza mesoporosa daqueles de paredes múltiplas; dessa forma, os primeiros exibem frequentemente área superficial específica mais elevada que os outros. No caso dos nanotubos de uma parede, a adsorção pode ocorrer dentro dos tubos (poros), nos canais intersticiais entre os tubos, na superfície externa ou nos sulcos formados pelo contacto entre tubos adjacentes na parte externa do agregado. Nos nanotubos de paredes múltiplas, os sítios de adsorção são constituídos por poros agregados, dentro dos tubos ou nas paredes externas; no último caso, a presença de defeitos, tal como uma camada incompleta de grafeno, deve ser considerada. As tendências observadas nas energias de ligação de gases, com diferentes raios de van der Waals, sugeriram que os sítios nos sulcos dos nanotubos de paredes múltiplas são os sítios preferenciais para baixos graus de cobertura, devido às suas elevadas energias de ligação. ${ }^{44}$

Os nanotubos e nanofibras de carbono têm sido extensivamente estudados como suportes catalíticos em diversas reações, tais como a hidrogenação do buteno, ${ }^{118}$ a hidrogenação do cinamaldeído, ${ }^{119}$ a decomposição do óxido de nitrogênio, ${ }^{120}$ a hidroformilação do etileno, ${ }^{121}$ a desidrogenação do ciclo-hexanol, ${ }^{122}$ a reação esqueletal do n-hexano, ${ }^{123}$ a oxidação do metanol, ${ }^{124}$ a decomposição do metano e na desidrogenação oxidativa do etilbenzeno para produzir estireno. ${ }^{125,126}$ Em particular, os nanotubos de paredes múltiplas e as nanofibras, quando utilizados para catalisar reações em fase líquida, apresentam a vantagem de diminuir significativamente as limitações de transferência de massa, em relação aos carvões ativados, devido à sua elevada área superficial específica e mesoporosidade. ${ }^{107}$ Entretanto, foram publicados poucos trabalhos abordando catalisadores baseados em nanotubos de paredes múltiplas, devido à sua microporosidade e à dificuldade de obter grandes quantidades do material puro, de modo a permitir estudos de catálise.

\section{Outras aplicações de nanomateriais em catálise}

Nos últimos dez anos muitos outros materiais, além do ouro e dos nanotubos de carbono, têm sido investigados como catalisadores. $\mathrm{O}$ potencial de aplicação desses sólidos está relacionado à sua elevada área superficial especifica e à possibilidade de controlar a seletividade, através de variações de tamanho das nanopartículas e dispersão no suporte. Os sistemas catalíticos baseados em óxido de alumínio, impregnados com nanopartículas de platina e paládio, com elevado grau de dispersão, por exemplo, são empregados em dispositivos automotivos para reduzir as emissões de poluentes atmosféricos. ${ }^{127}$

Entre os materiais, empregados como componentes de elétrodos de célula a combustível, encontram-se as nanopartículas de céria dopadas com terras raras. ${ }^{128}$ Em particular, o óxido de cério dopado com gadolínio e samário é considerado promissor, quando comparado ao eletrólito comercial baseado em zircônia estabilizada com ítrio, por permitir o uso de temperaturas de operação mais baixas que $800^{\circ} \mathrm{C}$, devido ao empregado como eletrólito em células a combustível de óxido sólido. Outro exemplo é apresentado pelas nanopartículas coloidais de platina-rutênio, obtidas pela redução de íons platina e rutênio com ácido cítrico e boro-hidreto de sódio, que são ativas na oxidação catalítica do metanol, reação de interesse industrial para a preparação de ânodo catalítico em células a combustível de metanol direta $\left(D M F C\right.$, Direct Methanol Fuel Cell). ${ }^{129} \mathrm{O}$ meio reacional mostrou-se adequado para obter nanopartículas desses metais com tamanhos entre 2 e $3 \mathrm{~nm}$, comprovando o seu potencial de aplicação como ânodo catalítico nas células DMFC.

As nanopartículas de óxido de cobalto suportados em óxido mistos de ceria-zircônia também apresentam potencial de aplicação como catalisadores, exibindo elevado desempenho na oxidação do metano em baixa temperatura. ${ }^{130}$ Outros estudos mostraram o potencial de catalisadores de platina suportados em óxidos mistos de cério e zircônio na reforma autotérmica do isooctano, na conversão de monóxido a dióxido de carbono a altas temperaturas e na remoção de óxidos de nitrogênio dos gases de exaustão automotivos. ${ }^{131,132}$

\section{CONCLUSÕES}

Os materiais nanoestruturados apresentam grandes promessas e oportunidades para uma nova geração de materiais com propriedades controladas e otimizadas, para diferentes aplicações, incluindo a catálise. Neste caso, se deseja alcançar atividades e seletividade perfeitas, similares àquelas das enzimas. Os nanocatalisadores possuem estruturas complexas, diferentes dos materiais em larga escala, com uma elevada superfície em relação ao volume, o que lhes confere propriedades únicas, especialmente reatividade. Entre esses materiais, os catalisadores de ouro constituem os exemplos mais marcantes de nanocatalisadores, sendo ativos em diferentes reações. Entretanto, o conhecimento sobre a natureza dos sítios catalíticos ainda é limitado, devido à carência de estudos nas condições das reações. Os nanotubos de carbono também apresentam grande potencial de aplicação em catálise, devido às suas propriedades eletrônicas, adsortivas, mecânicas e térmicas. Outros nanomateriais apresentam potencial de aplicação em catálise, tais como nanopartículas de platina, paládio, rutênio e céria suportadas.

Apesar do grande volume de trabalhos em nanocatalisadores, ainda existe carência do conhecimento da atuação desses materiais e de técnicas experimentais que possam produzir materiais em larga escala, com características reprodutíveis.

\section{AGRADECIMENTOS}

H. S. Ferreira agradece à CAPES pela bolsa de doutorado.

\section{REFERÊNCIAS}

1. Roco, M. C.; J. Nanoparticle Res. 2001, 3, 5.

2. Gai, P. L.; Roper, R.; White, M. G.; Curr. Opin. Solid State Mater. Sci. 2002, 6, 401.

3. Galembeck, F.; Rippel, M. M.; Parcerias Estratégicas 2004, nº18, 43.

4. Toma, H. E.; Quim.Nova, 2005, 28 Suplemento, S48.

5. Zhao, Q. Q.; Boxman, A.; Chowdhry, U.; J. Nanoparticle Res. 2003, 5, 567.

6. Rashba, E.; Gamota, D.; J. Nanoparticle Res. 2003, 5, 401.

7. Guo, S.; Wang, E.; Anal. Chim. Acta 2007, 598, 181.

8. Helland, A.; Kastenholz, H.; J. Cleaner Production 2008, 16, 885.

9. Uskoković, V.; Tecnology in Society 2007, 29, 43

10. Alves, O. L.; Parcerias Estratégicas 2004, nº18, 23.

11. Toma, H. E.; O Mundo Nanométrico: a dimensão do novo século, Ed. Oficina de Textos: São Paulo, 2004.

12. Bond, G.; Thompson, D.; Catal. Rev.-Sci. Eng.1999, 41, 39.

13. Kroto, H. W.; Heath, J. R.; O'Brien, S. C.; Curl, R. F.; Smalley, R. E.; Nature 1985, 318, 162. 
14. Iijima, S.; Nature 1991, $354,56$.

15. Tansil, N. C.; Gao, Z.; Nano Today 2006, 1, 28.

16. Daniel, M.-C.; Astruc, D.; Chem. Rev. 2004, 104, 293.

17. Kecskes, L. J.; Cho, K. C.; Dowding, R. J.; Schuster, B. E.; Valiev, R Z.; Wei, Q.; Mater. Sci. Eng. A 2007, doi :10.1016/j.msea.2007.02.099.

18. Mizuta, H.; Oda, S.; Microeletronics J. 2007, doi:10.1016/ J.mejo. 2006.10.007.

19. Raabe, D.; Sander, B.; Friák, M.; Ma, D.; Neugebauer, J.; Acta Materialia 2007, 55, 4475

20. Tiggelaar, R. M.; B-Lópes, F.; Hermes, D. C.; Rathgen, H.; Egberink, R. J. M.; Mugele, F. G.; Reinhoudt, D. N.; Berg, A. van den; Verboom, W.; Gardeniers, H. J. G. E. ; Chem. Eng. J. 2007, 131, 163.

21. Panigrahi, S.; Kundu, S.; Ghosh, S.; Nath, S.; Pal, T.; Colloids Surf. A: Physicochem. Eng. Aspects 2005, 264, 133.

22. Andreescu, D.; Kumar, T.; Goia, D. V.; J. Coll. Inter. Scien. 2006, 298 , 742 .

23. Cordente, N.; Toustou, B.; Collière, V.; Amiens, C.; Chaudret, B.; Verelst, M.; Respaud, M.; Broto, J.-M.; Acad. C. R.; Sci. Paris, Chimie 2001, 4, 143 .

24. P.-Juste, J.; P-Santos, I.; Liz-Marzán, L. M.; Muivaney, P.; Coord. Chem. Rev. 2005, 249, 1870

25. Boyd D.; Golunski, S.; Hearne, G. R.; Magadzu, T.; Mallick, K.; Raphulu, M. C.; Venugopal, A.; Scurrell, M. S.; Appl. Catal. A 2005, 292, 76.

26. Akolekar, D. B.; Bhargava, S. K.; Foran, G.; Takahashi, M.; J. Mol. Catal. A: Chem. 2005, 238, 78.

27. Thakur, S. K.; Srivatsan, T.S.; Gupta, M.; Mater. Scie. Eng. A 2007, 466,32

28. Goerke, O.; Pfeifer, P.; Schubert, K.; Appl. Catal. A 2004, 263, 11

29. Rossignol, C.; Arrii, S.; Morfin, F.; Piccolo, L.; Caps, V.; Rousset, J-L.; J. Catal. 2005, 230, 476

30. Ngomsik, A.-F.; Bee, A.; Draye, M.; Cote, G.; Cabuil, V.; C. R. Chimie $\mathbf{2 0 0 5}, 8,963$.

31. Losey, M. W.; Schmidt, M. A.; Jensen, K. E.; Ind. Eng. Chem. Res. 2001, 40, 2555

32. Britto, J. M.; Oliveira, S. B.; Rabelo, D.; Rangel, M. C.; Catal. Today 2008, 133-135, 582.

33. Oliveira, S. B.; Barbosa, D. P.; Monteiro, A. P. M.; Rabelo, D. Rangel, M. C.; Catal. Today 2008, 133-135, 92.

34. Rangel, M. C.; Pieck, C. L.; Pecchi, G.; Fígoli, N. S.; Reyes, P.; Ind. Eng. Chem. Res. 2001, 40, 5557.

35. Carvalho, L. S.; Rangel, M. C.; Pieck, C. L.; Fígoli, N. S.; Grau, J. M.; Reyes, P.; Parera, J. M.; Appl. Catal. A: Gen. 2004, 269, 91

36. Rangel, M. C.; Carvalho, L. S.; Fígoli, N. S.; Parera, J. M.; Pieck, C. L.; Vera, C. R.; Appl. Catal. A: Gen. 2004, 269, 105.

37. Somorjai, G. A.; Borodko, Y. G.; Catal. Lett. 2001, 76, 1.

38. Kung, H. H.; Kung, M. C.; Appl. Catal. 2003, 246,193.

39. Haruta, M.; J. Nanoparticle Res. 2003, 5, 3.

40. Zaera, F.; Somorjai, G. A.; Langmuir 1986, 2, 686.

41. Pieck, C. L.; Vera, C. R.; Parera, J. M.; Giménez, G. N.; Serra, L. R.; Carvalho, L. S.; Rangel, M. C.; Catal. Today 2005, 107, 637.

42. Dwyer, D. J.; Somorjai, G. A.; J. Catal. 1979, 56, 249.

43. Boffa, A. B.; Lin, C.; Bell, A. T.; Somorjai, G. A.; Catal. Lett. 1994, 27, 243

44. Grecco, S. T. F.; Gomes, L. P.; Reyes, P.; Oportus, M.; Rangel, M. C.; Stud. Surf. Sci. Catal. 2005, 158, 1937.

45. Kubo, R.; J. Phys. Soc. Jpn. 1962, 17, 975.

46. Friedel, I. J.; Ann. Phys. 1976, 1, 257.

47. Somorjai, G. A.; Introduction to Surface Science Chemistry and Catalysis, Willey: New York, 1994.

48. Somorjai, G.A.; Langmuir 1991, 7, 3176.

49. Alivisatos, P.; Nature 2000, 404, 59.

50. Eppler, A. S.; Zhu, J.; Anderson, E. A.; Somorjai, G. A.; Topics Catal. 2000, 13,3
51. Bradley, J. S.; Via, G. H.; Benneviot, L.; Hill, E. W.; Chem. Mater 1996, 8, 1895.

52. Henry, C. R. Em Nanocatalysis; Heiz, U.; Landman, U., eds.; SpringerVerlag: Berlim, 2007, p. 245

53. Taylor, K. J.; Pettiette, C. L.; Cheshnovsky, O.; Smalley, R. E.; J. Chem Phys. 1992, 96, 3319.

54. Vajda, S.; Wolf, S.; Leisner, T.; Busolt, U.; Wöste, L. H.; J. Chem. Phys. 1997, 107, 3492.

55. Holmgren, L.; Anderson, M.; Rosén, A.; J. Chem. Phys. 1998, 109, 3232

56. Albert, S.; Sanchez, A.; Heiz, U.; Schneider, W. D.; Ferrari, A. M.; Pacchioni, G.; Rösch, N.; J. Am. Chem. Soc. 2000, 122, 3453.

57. Freund, H. J.; Bäumer, M.; Libuda, J.; Risse, T.; Rupprechter, G.; Shaikhutdinov, S.; J. Catal. 2003, 216, 223.

58. Zhdanov, V. P.; Kasemo, B.; Phys. Rev. Lett. 1998, 81, 2482

59. Piednoir, A.; Perrot, E.; Granjeaud, S.; Humbert, A.; Chapon, C.; Henry, C. R.; Surf. Sci. 1997, 39,119.

60. Janssens, T. V. W.; Carlson, A.; Puig-Molina, A.; Clausen, B. S.; J. Catal. 2006, 240, 108.

61. Hardeveld, R. van; Hartog, F.; Surf. Sci. 1969, 15, 189.

62. Sanchez, A.; Abbet, S.; Heiz, U.; Schneider, W. D.; Häkkinen, H.; Barnett, R. N.; Landmanm, U.; J. Phys. Chem. A 1999, 103, 9573.

63. Marks, L. D.; Surf. Sci. 1985, 150, 358.

64. Mottet, C.; Tréglia, G.; Legrand, B.; Surf. Sci. 1997, 383, L719.

65. Marks, L. D.; Philos. Mag. A 1984, 49, 81.

66. Haruta, M.; Kobayashi, T.; Sano, H.; Yamada, N.; Chem. Lett. 1987, 405.

67. Wachs,I. E.; Gold Bull. 1983, 16, 98

68. Schwank, J.; Gold Bull. 1983, 16, 103.

69. Hardeveld, R. van; Hartog, F.; Surf. Sci. 1969, 15, 189.

70. Haruta, M.; Catal. Today 1997, 36, 153.

71. Haruta, M.; J. New Mater. Electrochem. Syst. 2004, 7, 163.

72. Hutchings, G. J.; Catal. Today 2005, 55, 100.

73. Landon, P.; Collier, P. J.; Papworth, A. J.; Kiely, C. J.; Hutchings, G. J.; Chem. Commun. 2002, 18, 2058

74. Nkosi, B.; Adams, M. D.; Coville, N. J.; Hutchings, G. J.; J. Catal. 1991, 128, 378

75. Adad, A.; Concepción, P.; Corma, A.; García, H.; Angew. Chem., Int Ed. 2005, 44, 4066

76. Carreira, S.; Guzman, J.; Corma, A.; Angew. Chem., Int. Ed. 2005, 44, 2242.

77. Corma, A.; Serna, P.; Science 2006, 313, 332.

78. Xu,Y.-J.; Serna, P.; Enache, D.; Carley, A. F.; Roberts, M. W.; Hutchings, G. J.; Catal. Lett. 2005, 101, 175

79. Corti, C. W.; Holliday, R. J.; Thompson, D. T.; Appl. Catal. A: Gen. 2005, 291, 253.

80. Gates, B. C.; G.-Fierro, J. C.; Catal. Today 2007, 122, 201.

81. Haruta, M.; Tsubota, S.; Kobayashi, T.; Kageyama, H.; Genet, M. J.; Delmon, B.; J. Catal. 1997, 144, 175.

82. Haruta, M.; Tsubota, S.; Kobayashi, T.; Kageyama, H.; Genet, M. J.; Delmon, B.; J. Catal. 1993, 144, 175.

83. Valden, M.; Lai, X.; Goodman, D. W.; Science 1998, 281, 1647.

84. Remediakis, I. N.; Lopez, N.; Nørskov, J. K.; Angew. Chem., Int. Ed. $\mathbf{2 0 0 5}, 44,1824$

85. Chen, M. S.; Goodman, D. W.; Science 2004, 306, 252

86. Costello, C. K.; Yang, J. H.; Law, H. Y.; Wang, Y.; Lin, J. N.; Marks, L. D.; Kung, M. D.; Kung, H. H.; Appl. Catal. A 2003, 243, 15.

87. Yoon, B.; Häkkinsen, H.; Landman, U.; Wörz, A. S.; Antonietti, J.-M.; Abbet, S.; Judai, K.; Heiz, U.; Science 2005, 307, 403.

88. Guzman, J.; Gates, B. C.; Angew. Chem., Int. Ed. 2005, 42, 690.

89. Okumura, M.; Nakamura, S.; Tsubota, S.; Nakamura, T.; Azuma, M.; Haruta, M.; Catal. Lett. 1998, 51, 53.

90. Haruta, M.; Daté, M.; Appl. Catal. A 2001, 222, 427. 
91. Remediakis, I. N.; Lopez, N.; Nørskov, J. K.; Angew. Chem., Int. Ed. 2005, 44, 2.

92. Piednoir, A.; Perrot, E.; Granjeaud, S.; Humbert, A.; Chapon, C.; Henry, C. R.; Surf. Sci. 1997, 39,119.

93. Cameron, D.; Holliday, R.; Thompson, D.; J. Power Sources 2003, 118 , 298.

94. Sakurai, H.; Akita, T.; Tsubota, S.; Kiuchi, M.; Haruta, M.; Appl. Catal. A 2005, 291, 179.

95. Wee, J.-H.; Lee, K.-Y.; J. Power Sources 2006, 157, 128.

96. Horváth, D.; Toth, L.; Guczi, L.; Catal. Lett. 2000, 67, 117.

97. Campo, B.; Volpe, M.; Ivanova, S.; Touroude, R.; J. Catal. 2006, 242, 162.

98. Sheng, P.-Y.; Bowmker, G. A.; Idriss, H.; Appl. Catal. A 2004, 261, 171.

99. Mellor, J. R.; Palazov, A. N.; Grigorova, B. S.; Greyling, J. F.; Reddy, K.; Letsoalo, M. P.; Marsh, J. H.; Catal. Today 2002, 72, 145.

100. Gluhoi, C. A.; Lin, S. D.; Nieuwenhuys, B. E.; Catal. Today 2004, 90, 175 .

101. Ilieva, L.; Pantaleo, G.; Sobczak, J. W.; Ivanov, I.; Venezia, A. M.; Andreeva, D.; Appl. Catal. B. 2007, 76, 107.

102. Ueda, A.; Oshima T.; Haruta, M.; Appl. Catal. B: Environ. 1997, 12, 81.

103. Ferreira, M. L.O.; Ferreira, H. S.; Frota, M.; Teixeira, V. L.; Rangel, M. C.; Livro de Anais do XV Congresso Argentino de Catálisis e $4^{\text {to }}$ Congresso de Catálisis del Mercosur, La Plata, Argentina, 2007.

104. Salama, T. M.; El-Bahy, Z. M.; Zidan, F. I.; J. Mol. Catal. A: Chem. 2007, 264, 128.

105. Sobczak, I.; Kusior, A.; Grams, J.; Ziolek, M.; J. Catal. 2007, 245, 259.

106. Yin, D.; Qin, L.; Liu, J.; Li, C.; Jin, Y.; J. Mol. Catal. A: Chem. 2005, 240, 40.

107. Serp, P.; Corrias, M.; Kalck, P.; Appl. Catal. A: Gen. 2003, 253, 337.

108. www.oviedo.es/personales/carbon/nanotubos/nanotubos.htm,acessada em Março 2008.

109. Romero, J. G. V.; Luengo, C. A.; Huber, J. C.; Rosolen, J. M.; Quim. Nova 2002, 25, 59.

110. Herbst, M. H.; Macêdo, M. I. F.; Rocco, A. M.; Quim. Nova 2002, 25, 59.

111. Fischer, J. E.; Johson, A. T.; Curr. Opin. Solid State Mater. Sci. 1999, $4,28$.
112. Bessel, C.A.; Laubernds, K.; Rodriguez, N. M.; Baker, R. T. K.; J. Phys. Chem. 2001, 105, 1115.

113. Bethume, D. S.; Klang, C. H.; Vries, M. S. D.; Gorman, J.; Nature 1993, 363, 605 .

114. Ouyang, M.; Huang, J.-L.; Liebre, C.M.; Acc. Chem. Res. 2002, 35, 1018.

115. Charlier, J.-C.; Acc. Chem. Res. 2002, 35, 1063.

116. Menon, M.; Andriotis, A. N.; Froudakis, G. E.; Chem. Phys. Lett. 2000, $320,425$.

117. Yang, Q. H.; Hou, P. X.; Bai, S.; Wang, M. Z.; Cheng, H.M.; Chem. Phys. Lett. 2001, 345, 18.

118. Park, C.; Baker, R. T. K.; J. Phys. Chem. B 1999, 103, 2453.

119. Giordano, R.; Serp, P.; Kalck, P.; Kihn, Y.; Schreiber, J.; Marhic, C.; Duvail, J.-L.; Eur. J. Inorg. Chem. 2003, 610.

120. Luo, J. Z.; Gao, L. Z.; Leung, Y. L.; Au, C. T.; Catal. Lett. 2000, 66, 91.

121. Gao, R.; Tan, C. D.; Baker, R. T. R.; Catal.Today 2001, 65, 19.

122. Liu, Z.-J.; Xu, Z.;Yuan, Z.-Y.; Lu, D.; Chen, W.; Zhou, W.; Catal. Lett. 2001, 72, 203

123. Baker, R. T. K.; Laubernds, K.; Wootsch, A.; Páal, Z.; J. Catal. 2000, $193,165$.

124. Bessel, C. A.; Laubernds, K.; Rodriguez, N. M.; Baker, R. T. K.; J. Phys. Chem. 2001, 105, 1115.

125. Shaikhutdinov, S. K.; Avdeeva, L. B.; Novgorodov, B. N.; Zaikovskii, V. I.; Kochubey, D. I.; Catal. Lett. 1997, 47, 35.

126. Su, D. S.; Maksimova, N. I.; Mestl, G.; Kuznetsov, V. L.; Keller, V.; Schlögl, R.; Keller, N.; Carbon 2007, 45, 2145.

127. Persson, K.; Ersson, A.; Colussi, S.; Trovarelli, A.; Järas, S. G.; Appl. Catal. B 2006, 66, 175.

128. Kang, H. S.; Sohn, J. R.; Kang, Y. C.; Jung, K. Y.; Park, S. B.; J. Alloys Compd. 2004, 374, 69.

129. Shimazaki, Y.; Kobayashi, Y.; Yamada, S.; Miwa, T.; Konno, M.; J. Colloid Interface Sci. 2005, 292,122

130. Liotta, L. F.; Carlo, G. Di; Pantaleo, G.; Deganello, G.; Catal. Commun. 2005, 6, 329.

131. Querino, P.; Bispo, J. R. C.; Rangel, M. C.; Catal. Today 2005, 108, 920.

132. Chen, L. F.; González, G.; Wang, J. A.; Norena, L. E.; Toledo, A.; Castillo, S.; M-Pineda, M.; Appl. Surf. Sci. 2005,243, 319. 